\title{
Optimum Design of Multidischarge Outlet Biomass Briquetting Machine
}

\author{
Jiaqi Yang $\left(\mathbb{C}^{1}{ }^{1}\right.$ Jirong Wang $\mathbb{D}^{1,2}{ }^{1,}$ Jun $\mathrm{Li}^{3}{ }^{3}$ Lianwen Shi, ${ }^{1}$ and Xiangwu Dai ${ }^{1}$ \\ ${ }^{1}$ College of Mechanical Engineering, Qingdao University, Qingdao 266300, China \\ ${ }^{2}$ Weihai Innovation Research Institute of Qingdao University, Weihai 264200, China \\ ${ }^{3}$ College of Computer Science and Technology, Qingdao University, Qingdao 266300, China \\ Correspondence should be addressed to Jirong Wang; wangjirong43@163.com
}

Received 20 August 2020; Revised 17 September 2020; Accepted 5 October 2020; Published 23 October 2020

Academic Editor: Qiang Chen

Copyright (@) 2020 Jiaqi Yang et al. This is an open access article distributed under the Creative Commons Attribution License, which permits unrestricted use, distribution, and reproduction in any medium, provided the original work is properly cited.

\begin{abstract}
A high-efficiency biomass material was designed according to the densification mechanism of biomass. This machine improved the efficiency by recombining the feeding stage, prepressing stage, compaction stage, pressure-holding stage, and pushing stage of the compression process, so that part of the working stages was carried out simultaneously. To further improve efficiency and rationally allocate power at each stage, in this paper, we established a mathematical model for the machine. We use the nonlinear programming in Matlab (2016b) to solve the minimum value of the model, making the machine work time the shortest.
\end{abstract}

\section{Introduction}

In nature, biomass resources are abundant, such as wheat straw, bean straw, straw, and corn straw. Carbon in biomass accounts for a large proportion, among which the carbon content of grain straw and corn straw can reach more than $40 \%$ [1]. The mass fraction of sulfur in straw is far less than that of coal, only $0.12 \% \sim 0.18 \%$ (the mass fraction of sulfur in coal is generally around $0.8 \%$ ) [2]. The cascading use of biomass to achieve a circular bioeconomy has been considered as a sustainable solution for an environmentally friendly world $[3,4]$. Producing bioenergy and biofuels to replace fossil fuels has been widely considered as an option of cascading biorefinery [5]. However, the low density, high moisture absorption, and comparatively low heating values of biomass limit the transportation, conversion, and combustion of biomass as solid fuels [6].

The densification of biomass is one of the essential preprocessing steps considered in the biomass conversion process for the successful use of biomass materials in various applications. This method has more efficient handling, storage, and transportation and uses of these biomass materials [7]. The present biomass material briquetting machine has low compression efficiency and high cost, which is not conducive to the spread of technology and limits the utilization rate of biomass resources [8-10].

\section{Densification Mechanism}

There are two main models of the biomass molding process: the stress-strain model and the density-pressure model. The stress-strain model divides the compression process into three stages: prepressing stage, compaction stage, and pressure-holding stage $[11,12]$. In the prepressing stage, the relative motion distance between the material particles is gradually reduced when the material is squeezed, but the material particles basically have not been deformed and do the irregular motion. It is not usual to model this stage. In the prepressing stage, the pressure increases. The distance among the material particles becomes closer and nested. The elastoplastic deformation of the material is generally represented by the viscoelastic model. This is the most critical stage. In the pressure-holding stage, the compacted material moves towards the outlet under the action of pressure. The phenomenon of stress relaxation (the stress drops slowly after reaching the maximum value) can be modeled by referring to the Burgess model $[13,14]$. To analyze the density-pressure relation, the Heckel is normally adopted 
[15]. It reflects the relationship between density and pressure in the forming process.

Both of these models can reflect the nonlinear processes of stress and strain, density, and pressure changes in the compression of birth material [16-18]. The force in the compaction stage is the largest cause of the material to undergo plastic deformation. It is a decisive factor in determining the quality of biomass briquetting products $[19,20]$.

\section{Parameter Optimization}

3.1. Material Selection. Select common materials, such as beanstalks, sawdust, wood shavings, Arundo donax, and acacia branches. Their density-pressure models are obtained by using the Heckel model.

The density of beanstalk before compression was $0.12\left(\mathrm{~g} / \mathrm{cm}^{3}\right)$. Generally speaking, the forming effect of the beanstalk is better, and the surface is basically smooth and clean. When the pressure is $10 \sim 15 \mathrm{MPa}$, the surface is rough, the material density is low, and the molding block is not compact and easy to fracture. When the pressure is more than $15 \mathrm{MPa}$, the molding effect becomes better. When the pressure is less than $40 \mathrm{MPa}$, the density increases at a faster rate as the pressure increases, while when the pressure is more than $40 \mathrm{MPa}$, the density increases at a slower rate. The fitting equation of density and pressure of beanstalk (Figure 1(a)) is as follows:

$$
\rho(P)=9 \times 10^{-6} P^{3}-0.0012 P^{2}+0.0552 P+0.4793 .
$$

The density of sawdust before compression was $0.16\left(\mathrm{~g} / \mathrm{cm}^{3}\right)$. The forming pressure is greater than $30 \mathrm{MPa}$, and the density of the pressing block does not change much with the increase of the pressure, floating up and down in a fixed value. When the pressure is more than $40 \mathrm{MPa}$, the surface of the forming block is carbonized due to the friction heat generated between the forming block and the mold cavity. The fitting equation of density and pressure of sawdust (Figure $1(\mathrm{~b})$ ) is as follows:

$$
\rho(P)=5 \times 10^{-6} P^{3}-0.0008 P^{2}+0.0359 P+0.5892 .
$$

The density of wood shavings before compression was $0.065\left(\mathrm{~g} / \mathrm{cm}^{3}\right)$. The forming blocks are compact. Although cracks appear on the surface of the forming blocks with a pressure of less than $25 \mathrm{MPa}$ after several days of placement, they are not easily broken and still meet the transportation requirements. When the pressure is greater than $40 \mathrm{MPa}$, the density of the pressing block has little change with the increase of the forming pressure. The fitting equation of density and pressure of wood shavings (Figure 1(c)) is as follows:

$$
\rho(P)=3 \times 10^{-7} P^{3}-9 \times 10^{-5} P^{2}+0.0064 P+0.7906 .
$$

The density of Arundo donax before compression was $0.155\left(\mathrm{~g} / \mathrm{cm}^{3}\right)$. When the pressure is between $10 \mathrm{MPa}$ and $25 \mathrm{MPa}$, the density of the pressing block increases with the pressure. When the pressure is greater than $40 \mathrm{MPa}$, the density of the pressing block is stable. The fitting equation of density and pressure of Arundo donax (Figure 1(d)) is as follows:

$$
\rho(P)=5 \times 10^{-6} P^{3}-0.0007 P^{2}+0.0331 P+0.5491 .
$$

The density of acacia branches before compression was $0.195\left(\mathrm{~g} / \mathrm{cm}^{3}\right)$. When the pressure is between $10 \mathrm{MPa}$ and $25 \mathrm{MPa}$, the density of the pressing block increases with the pressure. When the pressure is greater than $35 \mathrm{MPa}$, the density of the pressing block is stable. The fitting equation of density and pressure of acacia branches (Figure 1(e)) [21,22] is as follows:

$$
\rho(P)=2 \times 10^{-6} P^{3}-0.0003 P^{2}+0.0146 P+0.8961 .
$$

The target pressures of beanstalks, sawdust, wood shavings, Arundo donax, and acacia branches are $40 \mathrm{MPa}$, $30 \mathrm{MPa}, 40 \mathrm{MPa}, 40 \mathrm{MPa}$, and $35 \mathrm{MPa}$, respectively. The prepressing pressure is designed to be $10 \mathrm{MPa}$. In the prepressing stage, the material will be compressed into $1000 \mathrm{~cm}^{3}$ forming blocks, and then it will be compressed to the target pressure. According to the density-pressure fitting equation, the corresponding density under prepressing pressure and target pressure can be obtained. It can also be obtained that the maximum loading weight of a single prepress cavity is $M_{0}=\rho_{1} \times 1000 \mathrm{~cm}^{3}$ (Table 1 ).

\subsection{Design and Principle of Multidischarge Outlet Biomass} Briquetting Machine. The working stages of multidischarge outlets biomass briquetting machine are mainly divided into the feeding stage, prepressing stage, compaction stage, pressure-holding stage, and pushing stage. To improve production efficiency, the time of each stage is overlapped. The biomass briquetting machine is mainly composed of the rotary table, prepressing cavities, prepressing piston rods, compaction cavities, and compaction piston rods.

The rotary table has six prepressing cavities, and its cross section is a $100 \mathrm{~mm} \times 100 \mathrm{~mm}$ square (Figure 2). When three cavities are loaded and the other three cavities are precompressed, it has three compacted cavities with a cross section of $100 \mathrm{~mm} \times 100 \mathrm{~mm}$ square that can be moved on a $V$-shaped track. When one of the cavities works as a compacted cavity, the molding blocks from the previous cycle can be simultaneously pushed out. The molding blocks produced by the current cycle can hold pressure while the piston rods are going back. The compaction piston rods are composed of three parallel piston rods, which can simultaneously compress and push out the three forming blocks (Figure 3).

The production process of the machine: the hoppers feed the three prepress cavities on the rotary table, and the piston rods preload the other three. The compaction piston rods compact and push out the three molding blocks that are holding pressure in the previous cycle. The compaction and prepressing piston rods return to the starting position and the rotary table rotates $60^{\circ}$. The compaction cavities shift on the V-shaped track (Figure 4).

The pressure of the piston rods fast backward is $P_{3}=3 \mathrm{MPa}$. The total power of the machine is $30 \mathrm{~kW}$. 


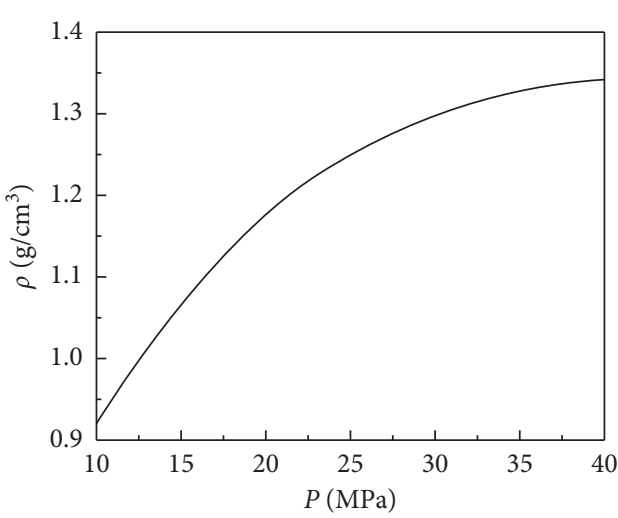

(a)

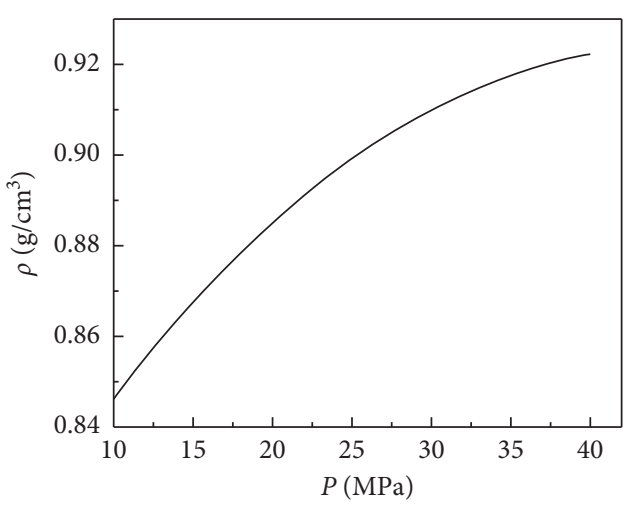

(c)

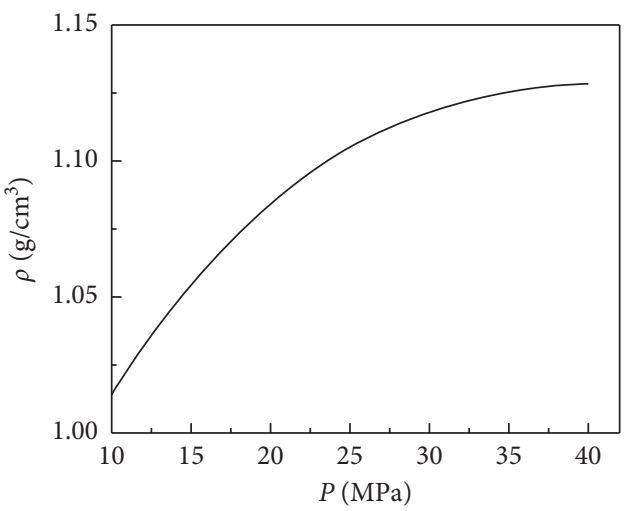

(e)

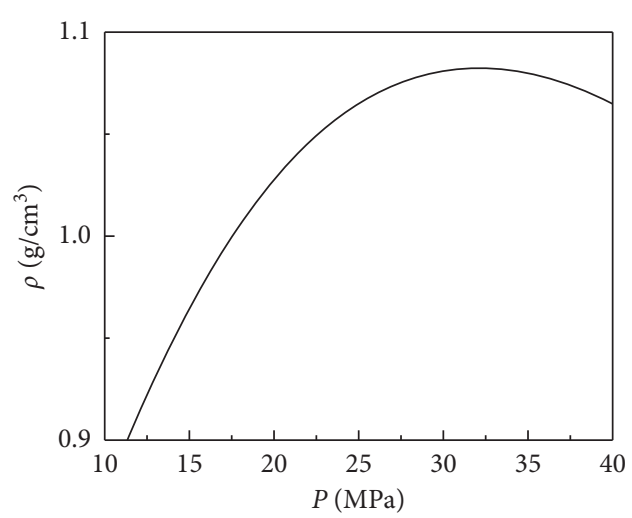

(b)

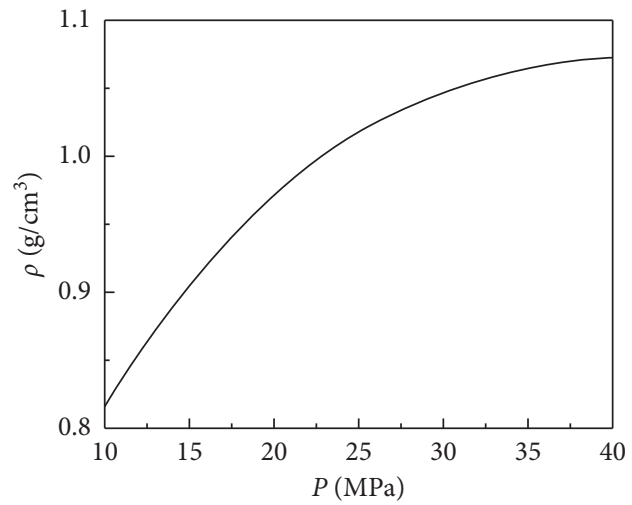

(d)

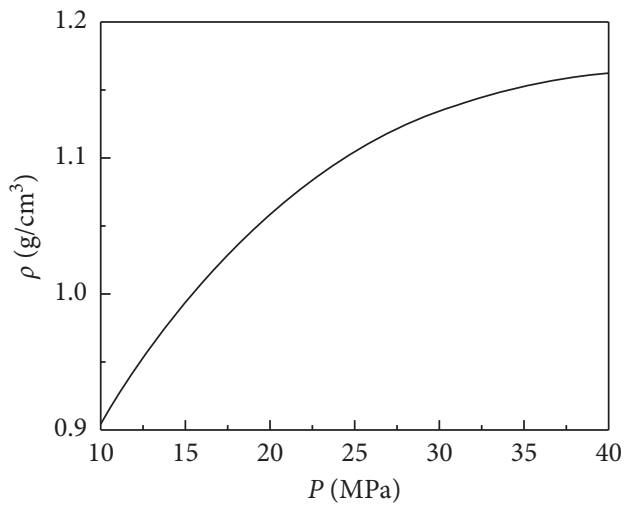

(f)

Figure 1: Density-pressure fitting curve. (a) Beanstalk. (b) Sawdust. (c) Wood shavings. (d) Arundo donax. (e) Acacia branches. (f) Average (above five materials).

3.3. Structural Analysis. Force analysis of a single compacted piston rod is given in Figure 5). The frictional force $F_{f}$ is negligible during compression. The relationship between the force of the hydraulic cylinder and the resistance of the material can be obtained $[23,24]$ :

$$
F_{P}=\frac{1}{3} F \tan \alpha,
$$

where $F_{P}$ is the resistance of the material, $F$ is the force of the hydraulic cylinder, $650 \mathrm{kN}$, and $\alpha$ is the angle between the hydraulic rod and the connecting rod.
It follows that the pressure $F_{P}$ of the compressed piston increases with $\alpha$ (Figure 6). $F$ increases fastest at $\alpha=60^{\circ}$, so 60 degrees is the boundary. When $\alpha<60^{\circ}$ is used for preloading, the pistons push the preloaded material into the compacted cavities. When $\alpha>60^{\circ}$ is used for material compaction.

The length of the connecting rod is designed as $L=380 \mathrm{~mm}$ (Figure 5). It can be concluded that the displacement $\Delta x$ of the compaction rod moves with $\alpha$ (Figure 7):

$$
\Delta x=L \sin \alpha-L \sin \alpha_{0},
$$


TABLE 1: The density and pressure of the key nodes during the compression process and the maximum loading weight of a single prepress cavity.

\begin{tabular}{lcccccc}
\hline $\begin{array}{l}\text { Material } \\
\text { name }\end{array}$ & $\begin{array}{c}\text { Initial density } \\
\rho_{0}\left(\mathrm{~g} / \mathrm{cm}^{3}\right)\end{array}$ & $\begin{array}{c}\text { Prepressing } \\
\text { pressure } P_{1}(\mathrm{MPa})\end{array}$ & $\begin{array}{c}\text { Prepressing density } \\
\rho_{1}\left(\mathrm{~g} / \mathrm{cm}^{3}\right)\end{array}$ & $\begin{array}{c}\text { Compaction } \\
\text { pressure } P_{2}(\mathrm{MPa})\end{array}$ & $\begin{array}{c}\text { Compaction density } \\
\rho_{2}\left(\mathrm{~g} / \mathrm{cm}^{3}\right)\end{array}$ & $\begin{array}{c}\text { Maximum loading } \\
\text { weight } M_{0}(\mathrm{~kg})\end{array}$ \\
\hline $\begin{array}{l}\text { Bean stalk } \\
\text { Sawdust }\end{array}$ & 0.120 & 10 & 0.920 & 40 & 1.343 & 0.920 \\
$\begin{array}{l}\text { Wood } \\
\text { shavings }\end{array}$ & 0.116 & 10 & 0.873 & 30 & 0.873 & 0.922 \\
$\begin{array}{l}\text { Arundo } \\
\text { donax }\end{array}$ & 0.065 & 10 & 0.846 & 40 & 1.065 & 0.846 \\
$\begin{array}{l}\text { Acacia } \\
\text { branches }\end{array}$ & 0.155 & 10 & 0.815 & 40 & 35 & 1.073 \\
\hline
\end{tabular}

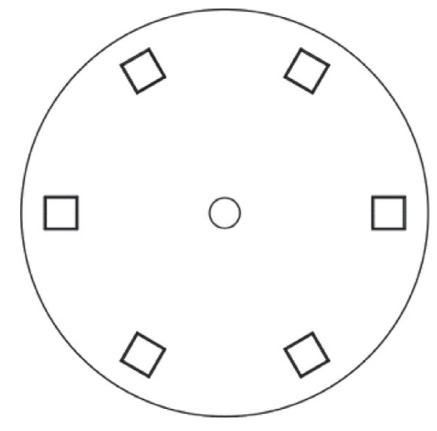

(a)

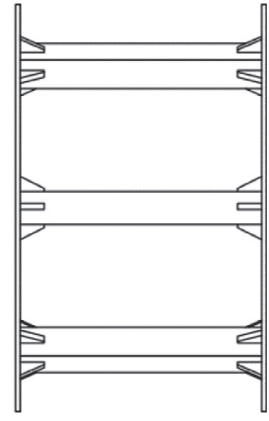

(b)

FIgURE 2: Rotary table.

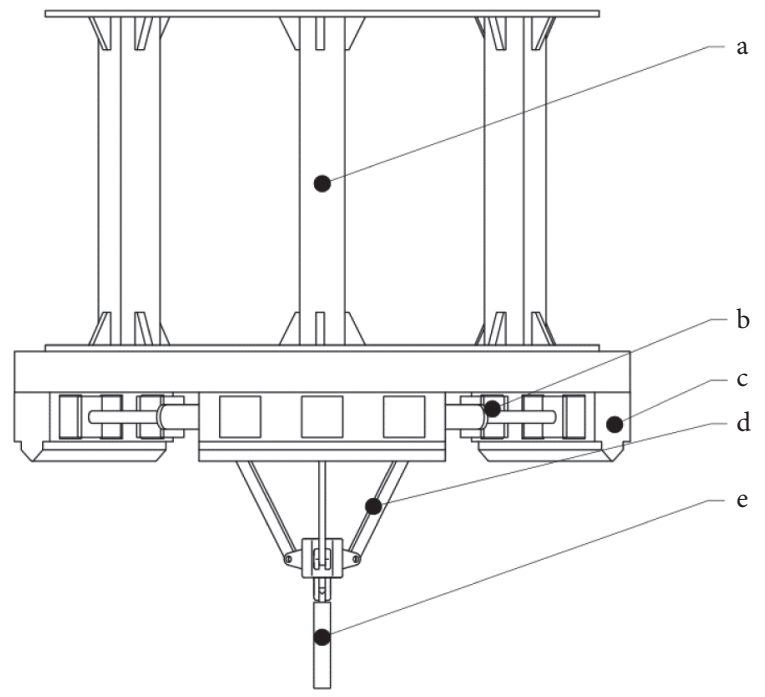

Figure 3: The structure of the machine. (a) Rotary table. (b) Compaction piston rod. (c) Compaction cavities. (d) Connecting rod. (e) Hydraulic cylinder piston rod.

where $\alpha_{0}$ is the initial angle.

It can be seen from Figure 7 that the movement speed of the compressed piston rods gradually decreases. In the process of compaction, the piston rods need to move $100 \mathrm{~mm}$ to push the prepressed material into the compaction cavities. In compaction stage, the displacement in the piston rods is less than $50 \mathrm{~mm}$. So, the initial angle $\alpha_{0}=42^{\circ}$ can be derived. the compaction initial angle $\alpha_{2}=60^{\circ}$.

Substituting (6) in $F_{P}=P S$, we get

$$
P=\frac{F \tan \alpha}{3 S}
$$

where $P$ is the pressure of material resistance and $S$ is the compacting piston head area, $100 \mathrm{~mm} \times 100 \mathrm{~mm}$ :

$$
\begin{aligned}
\therefore \Delta \rho(P) & =\frac{M_{0}}{V}=\frac{M_{0}}{S \cdot \Delta l}, \\
\therefore \Delta l & =\frac{M_{0}}{\Delta \rho(P) S},
\end{aligned}
$$

where $M_{0}$ is the material weight per time and $\Delta l$ is the length of the side in the material forming process:

$$
\therefore b-\Delta x=\Delta l \text {, }
$$

where $b$ is the side length of the material after precompression, $100 \mathrm{~mm}$ :

$$
\therefore b-\left(L \sin \alpha-L \sin \alpha_{2}\right)-\frac{M_{0}}{\Delta \rho(P) S}=0 \text {. }
$$

This implicit equation can reflect the relationship between material pressure and $\alpha$ during the compaction stage.

It can be seen from Figure 8 that the material resistance pressure can meet the compression requirements of all kinds of material with the variation trend. During the movement 


\begin{tabular}{|l|c|c|c|c|}
\hline Stage & Prepressing stage & $\begin{array}{c}\text { Compaction } \\
\text { stage }\end{array}$ & $\begin{array}{c}\text { Fast } \\
\text { backward }\end{array}$ & $\begin{array}{c}\text { Pressure-holding } \\
\text { stage }\end{array}$ \\
\hline Hopper & $\begin{array}{c}\text { Feed 1,3,5 } \\
\text { prepressing cavities }\end{array}$ & \multicolumn{3}{|c|}{ Pause } \\
\hline $\begin{array}{l}\text { Prepressing } \\
\text { piston rod }\end{array}$ & $\begin{array}{c}\text { Prepress 2, 4,6 } \\
\text { prepressing cavities }\end{array}$ & Pause & Return & Pause \\
\hline $\begin{array}{l}\text { Compaction } \\
\text { piston rod }\end{array}$ & Pause & $\begin{array}{l}\text { Compact 2, 4,6 } \\
\text { forming blocks }\end{array}$ & \multirow{2}{*}{ Return } & \multirow{2}{*}{ Pause } \\
\cline { 2 - 3 } & \multicolumn{2}{|c|}{ Push out } & Rotate $60^{\circ}$ \\
\hline Rotary table
\end{tabular}

FIgURE 4: Sequence diagram.

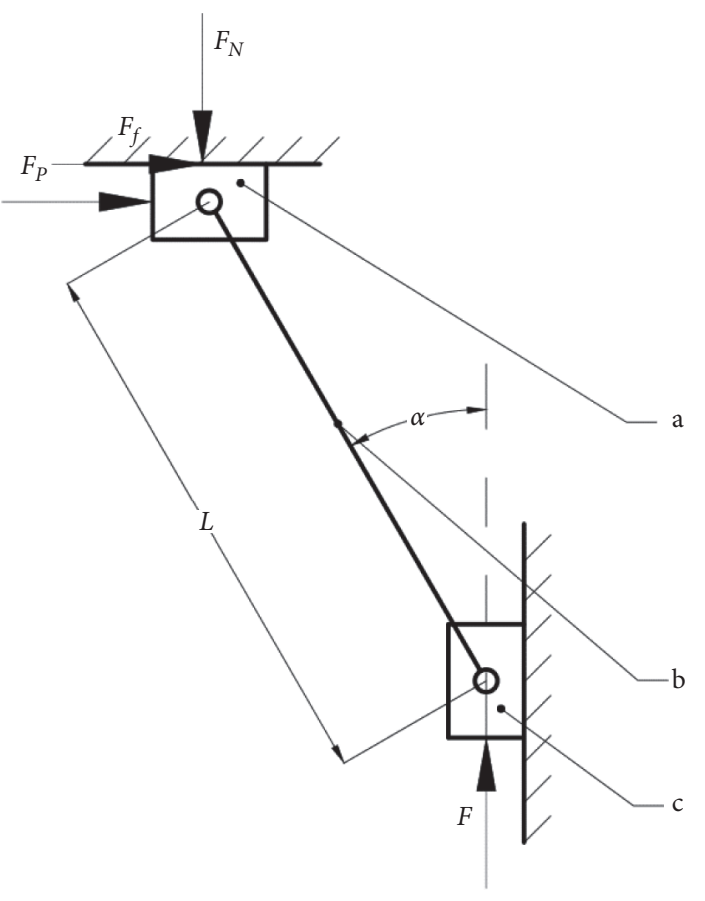

Figure 5: Force analysis of a single compacted piston rod. (a) Compaction piston rod. (b) Connecting rod. (c) Hydraulic cylinder piston rod.

of the compressed piston, the target pressure of the material can be reached by the uniform motion of the cylinder [25].

\subsection{Mathematical Modeling}

\subsubsection{Hypotheses}

(a) The biomass materials used strictly conform to the density-pressure fitting equation. In the process of compression, the mass of the material does not change and the volume decreases.

(b) Ignore the start and stop time of each cylinder. The hydraulic cylinder moves at a constant speed. The optimization process ignores the influence of various factors in the process of starting the machine. The target cycle is the working cycle after the machine is working smoothly.

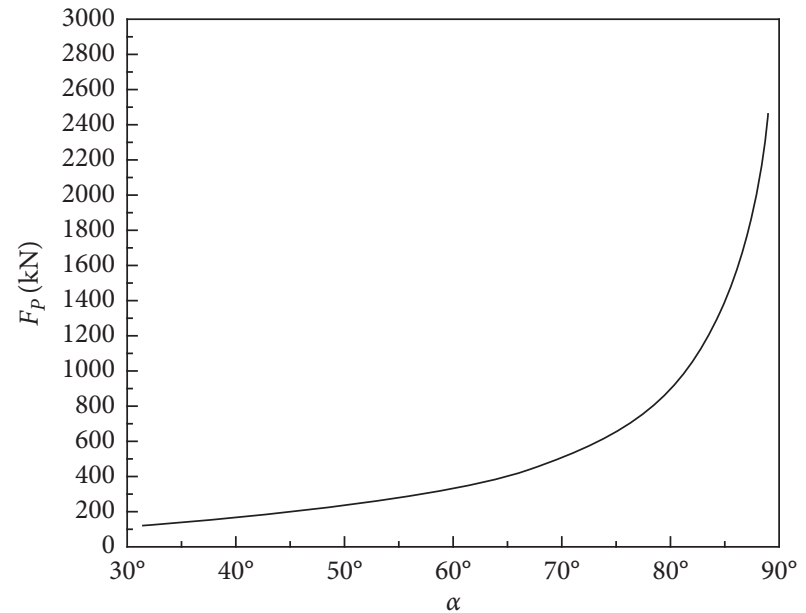

Figure 6: The relationship between the force of the hydraulic cylinder and the resistance of the material.

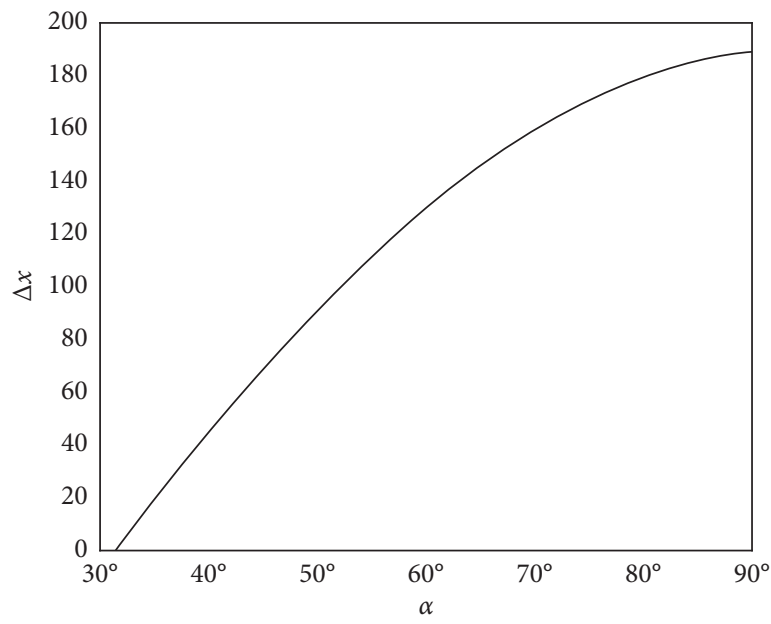

FIGURE 7: The displacement $\Delta x$ of the compaction rod moves with $\alpha$.

3.4.2. Modeling. The sequence diagram (Figure 4) shows that the machine has four stages in its working cycle. They are prepressing stage, compaction stage, fast backward stage, and pressure-holding stage. So, the target function is 


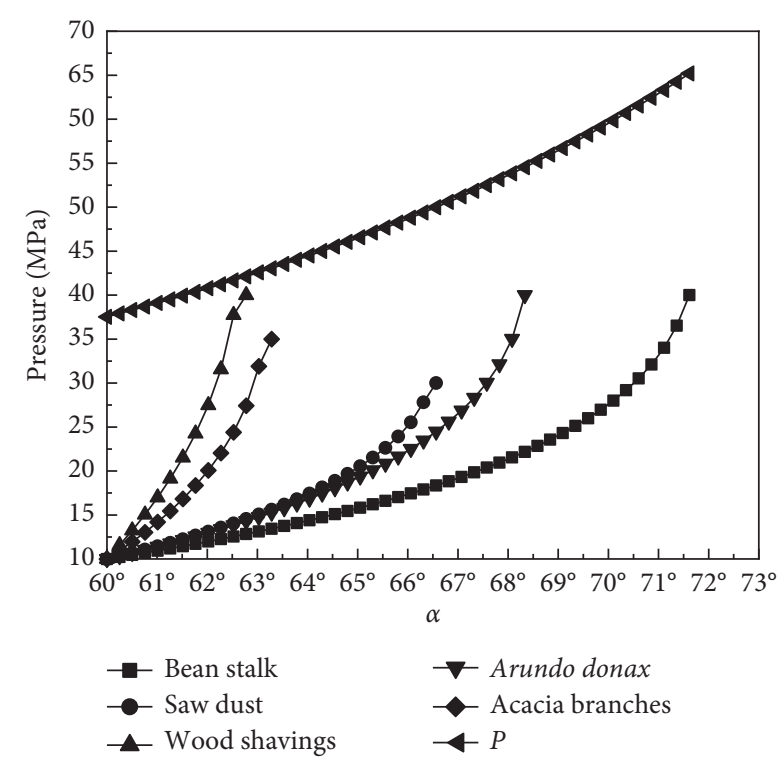

FIgURE 8: The relationship between material pressure and $\alpha$.

$$
\min f(X)=\left(x_{1}+x_{2}+x_{3}+x_{4}\right)
$$

where $x_{1}$ is the time of the prepressing stage, $s ; x_{2}$ is the time of the compaction stage, $s ; x_{3}$ is the time of the fast backward stage, $s ; x_{4}$ is the time of the pressure-holding stage, $\mathrm{s}$ :

$$
x_{1}=\frac{P_{1} \cdot S}{N_{1}} \cdot\left(\frac{M_{0}}{\rho_{0} \cdot S}-\frac{M_{0}}{\rho_{1} \cdot S}\right)=\frac{P_{1}}{N_{1}} \cdot\left(\frac{M_{0}}{\rho_{0}}-\frac{M_{0}}{\rho_{1}}\right) \text {. }
$$

Similarly,

$$
\begin{aligned}
& x_{2}=\frac{P_{2}}{N_{2}} \cdot\left(\frac{M_{0}}{\rho_{1}}-\frac{M_{0}}{\rho_{2}}\right), \\
& x_{3}=\frac{P_{3}}{N_{3}} \cdot\left(\frac{M_{0}}{\rho_{0}}-\frac{M_{0}}{\rho_{1}}\right) .
\end{aligned}
$$

where $x_{4}$ takes a quarter of the total cycle time:

$$
x_{4}=\frac{1}{4} t .
$$

where $N_{i}$ is the power of each stage, $\mathrm{kw}(i=1,2,3)$.

The objective function can be converted to

$$
\left\{\begin{array}{l}
\min f(X)=\frac{4}{3}\left(\frac{P_{1}}{N_{1}} \cdot\left(\frac{M_{0}}{\rho_{0}}-\frac{M_{0}}{\rho_{1}}\right)+\frac{P_{2}}{N_{2}} \cdot\left(\frac{M_{0}}{\rho_{1}}-\frac{M_{0}}{\rho_{2}}\right)+\frac{P_{3}}{N_{3}} \cdot\left(\frac{M_{0}}{\rho_{0}}-\frac{M_{0}}{\rho_{1}}\right)\right), \\
\text { s.t. } N_{1}+N_{2}+N_{3}-30 \leq 0, \\
N_{1}-N_{2}+5 \leq 0, \\
-N_{2}+N_{3}+5 \leq 0, \\
-N_{1}+N_{3} \leq 0, \\
N_{1}-15 \leq 0, \\
N_{2}-30 \leq 0, \\
N_{3}-15 \leq 0, \\
-N_{1} \leq 0,
\end{array}\right.
$$


TABLE 2: Calculation results.

\begin{tabular}{|c|c|c|c|c|c|c|}
\hline Material & $N_{1}(\mathrm{~kW})$ & $N_{2}(\mathrm{~kW})$ & $N_{3}(\mathrm{~kW})$ & $x(\mathrm{~s})$ & $1 / 3 x(s)$ & Efficiency $(\mathrm{kg} / \mathrm{min})$ \\
\hline Bean stalk & 9.105 & 14.105 & 6.790 & 14.881 & 4.960 & 11.128 \\
\hline Saw dust & 9.053 & 14.053 & 6.895 & 13.911 & 4.637 & 11.296 \\
\hline Wood shavings & 9.025 & 14.025 & 6.951 & 24.980 & 8.327 & 6.096 \\
\hline Arundo donax & 9.123 & 14.123 & 6.755 & 9.653 & 3.218 & 15.197 \\
\hline Acacia branches & 9.053 & 14.053 & 6.893 & 8.958 & 2.986 & 20.374 \\
\hline Average & 9.072 & 14.072 & 6.857 & 14.477 & 4.826 & 12.818 \\
\hline
\end{tabular}

\section{Conclusions}

Nonlinear programming in Matlab (2016b) was used to solve the model minimum value which made the machine work in the shortest time. The average production time of each molding block is $1 / 3 t$. The production efficiency and average value can be calculated (Table 2).

The calculation results show the following:

(1) In the design of multidischarge outlet biomass briquetting machine, reasonably arrange each stage of work, so that some stages at the same time, to improve efficiency. By optimizing the design, the power of each stage of the equipment is allocated reasonably to further improve the production efficiency. Compared with the time it takes to produce a single product by rotary molding machine, the multidischarge outlet biomass briquetting machine has improved [26].

(2) The compression time of the material is related to its compression ratio. For example, the wood chip is compacted inside, with low compression and high compression difficulty. The highest power and longest time are required in the compaction stage, resulting in low production efficiency. Therefore, the multidischarge outlet biomass briquetting machine is more suitable for soft and large compression ratio materials.

(3) When compressing materials with a low compression ratio, the power of the whole machine can be appropriately increased, to improve the efficiency. For example, increasing the compression power of wood chips to $40 \mathrm{~kW}$ can reduce the time to $17.868 \mathrm{~s}$.

\section{Data Availability}

The data used to support the findings of this study are available from the corresponding author upon request.

\section{Conflicts of Interest}

The authors declare that they have no conflicts of interest.

\section{References}

[1] L. Weizhen, J. Yang, W. Gongliang et al., "Progress in research of biomass molding mechanism," Renewable Energy Resources, vol. 34, no. 10, pp. 1525-1532, 2016.
[2] C. Zheng and B. Deng, "Analysis of straw generating technology and selection of equipments," Water Conservancy \& Electric Power Machinery, vol. 7, pp. 42-45, 2006.

[3] W. Liang and J. Liu, Treatment and Recycling of Crop Straw, Chemical Industry Press, Beijing, China, 2018.

[4] C. Patermann and A. Aguilar, "The origins of the bioeconomy in the European Union," New Biotechnology, vol. 40, pp. 20-24, 2018.

[5] B. Song and P. Hall, "Densification of biomass and waste plastic blends as a solid fuel: hazards, advantages, and perspectives," Frontiers in Energy Research, vol. 8, p. 58, 2020.

[6] A. Friedl, E. Padouvas, H. Rotter, and K. Varmuza, "Prediction of heating values of biomass fuel from elemental composition," Analytica Chimica Acta, vol. 544, no. 1-2, pp. 191-198, 2005.

[7] N. Kaliyan, R. V. Morey, M. D. White, and A. Doering, "Roll press briquetting and pelleting of corn stover and switchgrass," Transactions of the Asabe, vol. 52, no. 2, pp. 543-555, 2009.

[8] M. Fu, W. Guo, and D. Liang, "Current status of biomass briquetting forming equipment," Science and Technology Innovation Herald, vol. 12, no. 17, pp. 137-141, 2015.

[9] M. Ahiduzzaman and A. K. M. S. Islam, "Development of biomass stove for heating up die barrel of rice husk briquette machine," Procedia Engineering, vol. 56, pp. 777-781, 2013.

[10] Q. Zhao, "Design of biomass fuel compaction machine based on vibration theory," Electronic Test, vol. 1, pp. 13-14, 2017.

[11] H. U. Jian-jun, L. Ting-zhou, and S. Sheng-qiang, "Regression analysis on specific energy consumption in the pelletizing process of straw," Renewable Energy Resources, vol. 28, no. 1, pp. 29-32, 2010.

[12] L. Zhen, W. Hongqiang, and G. Yuhang, "Bonding mechanism of dense forming of salix biomass fuel particles," Transactions of the CSAE, vol. 35, no. 21, pp. 235-241, 2019.

[13] W. Li, Y. Jiang, and X. Yin, "Research situation of compression mechanism of biomass molding fuel at home and abroad," Journal of Circuits and Systems, vol. 5, no. 4, pp. 286-293, 2017.

[14] K. Sheng and J. Wu, "Review on physical properties and forming mechanisms of biomass briquettes," Transactions of the CSAE, vol. 20, no. 2, pp. 242-245, 2004.

[15] R. W. Heckel, "Density-pressure relationships in powders compaction," Transactions of the Metallurgical Society of AIME, vol. 1, no. 104, pp. 47-63, 2009.

[16] N. Kaliyan and R. V. Morey, "Constitutive model for densification of corn stover and switchgrass," Biosystems Engineering, vol. 104, no. 1, pp. 47-63, 2009.

[17] F. Wang, L. Chang, and Y. Li, "Simulation analysis of straw compression molding process," Journal of Agricultural Mechanization Research, vol. 36, no. 12, pp. 230-235, 2014.

[18] Z. Niu, Y. Lei, and B. Yang, "Finite element analysis of forming sleeve for biomass molding machine based on Creo 
simulate," Journal of Chinese Agricultural Mechanization, vol. 40, no. 1, pp. 68-71, 2019.

[19] P. Zuo, J. Ji, R. Tadmor, and J. Liu, "Wrinkling number and force of a particle raft in compression," The European Physical Journal E, vol. 42, no. 11, 2019.

[20] P. Zuo, J. Liu, and S. Li, "The load-bearing ability of a particle raft under the transverse compression of a slender rod," Soft Matter, vol. 13, no. 12, pp. 2315-2321, 2017.

[21] C. Hui and G. Yu, "A study on the influencing factors of bimass briquette forming with high pressure of general concitions of bio-materials solidification fuel," Forestry $\mathrm{Ma}$ chinery \& Woodworking Equipment, vol. 11, pp. 10-14, 2005.

[22] C. Hui, The Studies of Biomass Solidifying Technology and Principle with High Pressure on Natural Conditions for BioFuel Making, Springer, Berlin, Germany, 2006.

[23] X. Zhao, W. Huang, and M. Zhao, "YK-3 biomass briquetting machine research and design," Journal of Chinese Agricultural Mechanization, vol. 34, no. 4, pp. 154-157, 2013.

[24] G. Wu, Y. Liu, and F. Lu, "Optimum design of the molding drum of the piston punch biomass briquetting machine," Journal of Henan Agricultural University, vol. 51, no. 3, pp. 341-347, 2017.

[25] J. I. Orisaleye, S. J. Ojolo, and J. S. Ajiboye, "Mathematical modelling of die pressure of a screw briquetting machine," Journal of King Saud University -Engineering Sciences, vol. 21, no. 1, pp. 122-133, 2019.

[26] N. Bu, J. Wang, and J. Li, "Optimal design of revolving agrostalks compressor," Machinery, vol. 37, no. 2, pp. 56-58, 2010. 